\title{
CHARACTERISTICS OF TRAFFIC INDUCED- VIBRATION OF GROUND FILLED WITH LIQUEFIED STABILIZED SOIL MADE FROM EXCAVATED VINH PHUC CLAY IN HANOI CITY, VIETNAM
}

\author{
Nguyen Cong Giang \\ Doctor of Engineering, Hanoi Architectural University \\ (Km 10 Nguyen Trai Road, Dong Da District, Hanoi-Vietnam) \\ Seiji Nishiyama \\ Doctor of Engineering, Nikken Sekkei Civil Engineering Ltd \\ (4-6-2 Komyobashi, Chuo-ku, Osaka 541-8528, Japan) \\ Yukihiro Kohata \\ Doctor of Engineering, Muroran Institute of Technology \\ (27-1 Mizumoto-cho, Muroran-shi. 050-8585, Japan)
}

\begin{abstract}
At Hanoi city, the subway system has been constructed for the purpose of modernizing the transportation network. In general, mountain sand is used as backfill of such open-cut transportation tunnels. Recently, for the protection of environment, reuse of excavated soil has been promoted. The characteristics of traffic inducedvibration depend on the stiffness and thickness of sub-layers. It is possible that the traffic induced-vibration can be reduced by the characteristics of backfill. In this paper, using two-dimensional FEM, the characteristics of traffic induced-vibration of ground filled with the liquefied stabilized soil made from excavated Vinh Phuc clay in Hanoi will be compared with those of ground filled with mountain sand.
\end{abstract}

Keywords: traffic induced-vibration, backfill, liquefied stabilized soil, Vinh Phuc clay, open-cut tunnel

Cite this Article: Nguyen Cong Giang, Seiji Nishiyama and Yukihiro Kohata, Characteristics of traffic induced-vibration of ground filled with liquefied stabilized soil made from excavated Vinh Phuc clay in Hanoi city, Vietnam, International Journal of Civil Engineering and Technology, 11(4), 2020, pp. 36-53.

http://www.iaeme.com/IJCIET/issues.asp?JType=IJCIET \&VType=11\&IType=04 


\section{INTRODUCTION}

In general, mountain sand is used for backfilling of open-cut tunnels. However recently, the opportunities of using liquefied stabilized soil method has increased due to environmental aspects such as workability, reuse of excavated soil and environmental preservation of borrow pits.

On the other hand, with the recent increase in the awareness of the living environment, there are concerns about the surrounding ground vibration caused by traffic loads on roads and railways, and the number of cases examined is increasing.

The vibration characteristics of the ground due to traffic loads greatly affect the hardness of the ground layers as well as the thickness of those layers as ground conditions. When a car running on the road surface is used as the vibration source, the backfill soil is the ground supporting the road structure, which may affect the vibration behavior. However, the effect of backfill soil on ground vibration has not been studied so far.

Therefore, the authors analytically considered the vibration characteristics of the ground when changing the characteristics of the backfilled part by two-dimensional FEM, mainly in the case of backfilling with mountain sand and the case of using liquefied stabilized soil 1). The target was not only the traffic load on the ground surface but also the traffic load inside the tunnel. However, since past research aimed to grasp the rough effect of vibration reduction, only the average reduction effect in the $50 \mathrm{~m}$ section from the excitation position was considered. The results at fixed points $(10 \mathrm{~m}$ and $20 \mathrm{~m}$ from the public-private boundary and the road center) where normal vibrations were measured have not been examined. Therefore, in this paper, the vibration reduction effect at each distance is also examined in more detail.

Furthermore, in the previous study 1), the vibration characteristics of traffic loads on the ground surface and of traffic loads in the tunnel were examined by the displacement trajectory. However, the target excitation position was only ground surface excitation. From the viewpoint of effective underground use in recent years, it is also useful to consider the vibration phenomenon by visualizing the displacement trajectory in the same way for underground vibrations such as subways. Therefore, in the case of underground excitation, the vibration trajectory is also visualized and compared with ground excitation.

Through these studies, the purpose of this research is to understand the traffic vibration reduction effect when liquefied stabilized soil is used as backfill soil for open-cut tunnels.

\section{STUDY CONDITIONS}

Fig. 1 shows the open-cut tunnel to be examined, and Fig. 2 shows the ground conditions. These are assumed to be in Hanoi, the capital city of Vietnam, for the project the authors are involved in.

Hanoi, Vietnam, is located about $100 \mathrm{~km}$ upstream from the mouth of the Red River. Its altitude is 4 20 m above sea level, and thick sediments mainly composed of clay particles carried by the Red River are accumulated. Currently, serious traffic jams are occurring daily in Hanoi due to the concentration of industrial areas and population growth. One of the priority developments is the enhancement of the city traffic network, especially the subway network. In addition, the construction of the subway is planned to be proceeded by the open-cut tunnel method in which the existing road is excavated, then a tunnel is constructed, then finally the original road is refilled.

The subway is planned as an open-cut tunnel with a diameter of about $4 \mathrm{~m}$, a width of 10 $\mathrm{m}$, and a height of $7 \mathrm{~m}$. The ground is an alternating layer of soft clayish soil or loose sandy 
soil from the surface to the depth of about $30-40 \mathrm{~m}$, and a tight sand layer or gravel layer from the depth of about 30-40 $\mathrm{m}$ and deeper.

Since the surrounding ground is soft, ground vibration due to traffic vibration may become a problem. Therefore, the automobile load on the ground surface (surface excitation) and the train load inside the subway (underground excitation) are used as excitation sources to consider.

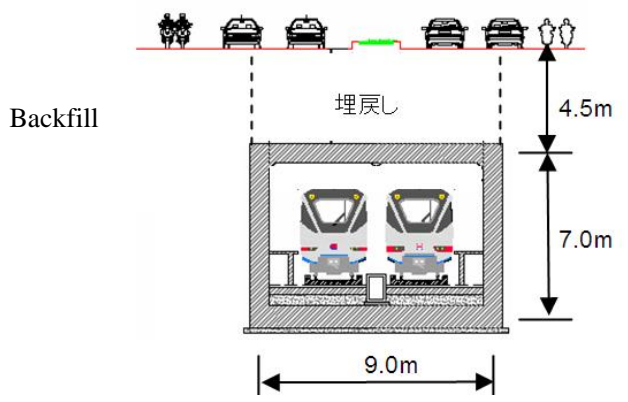

Figure 1 Analysis object

Table 1 Physical properties of Vinh Phuc Clay

\begin{tabular}{|c|c|}
\hline Soil classification & {$[$ CL] } \\
\hline Soil particle density $\left(\mathrm{g} / \mathrm{cm}^{3}\right)$ & 2.722 \\
\hline Liquid limit $(\%)$ & 38.2 \\
\hline Plastic limit $(\%)$ & 16.5 \\
\hline Plasticity index & 21.7 \\
\hline
\end{tabular}

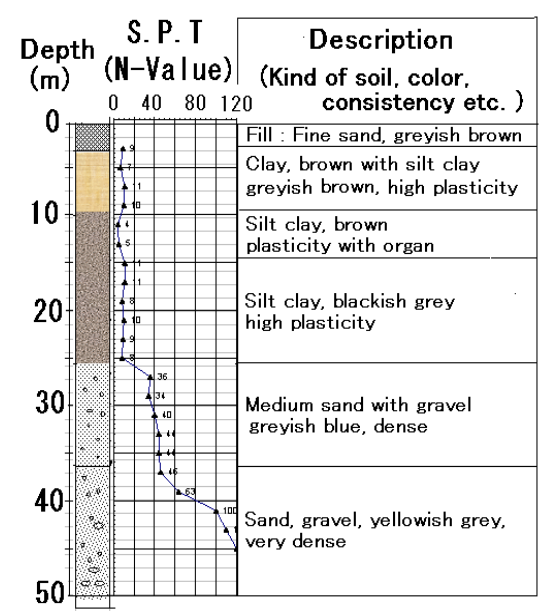

Figure 2 Ground conditions

\section{CHARACTERISTICS OF BACKFILL SOIL}

\subsection{Characteristics of liquefied stabilized soil}

\subsubsection{Raw material characteristics}

Liquefied stabilized soil was made from Vinh Phuc Clay collected from around the planned subway site in Hanoi, Vietnam. The physical properties are shown in Table-1. This Vinh Phuc 
Clay is classified as low liquid limit clay (CL). According to X-ray diffraction, this clay also contains mica, kaolinite, etc., but it is characterized mainly by quartz.

About the solidifying material, a cement-based solidifying material for general soft soil (Pacific cement; Geoset 10) was used.

\subsubsection{Formulation and characteristics}

The density of muddy water and the addition amount of solidification material were set to 1.350 $\mathrm{g} / \mathrm{cm}^{3}$ and $200 \mathrm{~kg} / \mathrm{m}^{3}$ respectively, from the characteristic values obtained by the flow test, breathing test, and unconfined compression test after 28 days of curing.

\subsubsection{Stiffness $\cdot$ Specific weight}

The authors are separately investigating the performance improvement of liquefied stabilized soil by adding fibers to it ${ }^{2}$. Using deformation coefficient $\mathrm{E}_{0}=587600 \mathrm{kN} / \mathrm{m}^{2}$ (constraint pressure $49 \mathrm{kPa}$, no fiber added) calculated from the results of laboratory triaxial test, unit volume weight $\gamma=14.0 \mathrm{kN} / \mathrm{m}^{3}$, shear elastic modulus $\mathrm{G}=197200 \mathrm{kN} / \mathrm{m}^{2}$ were chosen as the basic setting of liquefied stabilized soil.

\subsection{Characteristics of mountain sand (backfill material)}

There are few survey results on the rigidity of backfill materials. Here, $\mathrm{N}$ value $=10$ and specific weight $\gamma=17.0 \mathrm{kN} / \mathrm{m} 3$ were set with reference to the survey results of backfill soil (decomposed granite soil) of Daikai Station ${ }^{3)}$ which was damaged by the Great Hanshin Earthquake. The shear elastic modulus $\mathrm{G}=51531 \mathrm{kN} / \mathrm{m}^{2}$ was set by converting from the $\mathrm{N}$ value using the Railway design standard ${ }^{4)}$.

\section{FREQUENCY CHARACTERISTICS OF TRAFFIC LOAD}

\subsection{Surface traffic load}

The traffic loads on the ground surface can be considered to be a load from cars or trains that travels on the ground. The frequency characteristics of these traffic loads are summarized as below.

First, there have been reports of cases in which ground vibrations of about $10 \sim 20 \mathrm{~Hz}$ predominate with automobile loads ${ }^{5}$. Since ground vibration is greatly affected by the surrounding ground conditions, it is difficult to describe a uniform tendency. However, vibrations with low frequency up to about $10 \mathrm{~Hz}$ are transmitted far away without being attenuated on relatively soft ground as ground surface waves. On the other hand, a high frequency of about $30 \sim 40 \mathrm{~Hz}$ is caused by automobile body and the unevenness of the road surface. A high frequency is relatively easy to attenuate, and it is difficult to feel with human senses. However, there are many cases that people inside a building complain due to the resonance of high vibration with the natural frequency of the building's partial vibration system and the high frequency being converted into solid sound of window glass and such. Therefore, it is necessary to cover not only vibrations around $4 \sim 8 \mathrm{~Hz}$, which are easy for the human body to feel, but also frequencies up to around $40 \mathrm{~Hz}$, which is relatively high.

On the other hand, with regard to the train load, since both the top and the bottom of a bogie train is a vibrating body, a train also generates a wide range of frequency components. There is a report that the frequency level around $31.5 \mathrm{~Hz}^{6}$ is high in a terrestrial train, and it is better to also target relatively high vibrations of $20 \sim 40 \mathrm{~Hz}$ as vibrations for train loads. 
Characteristics of traffic induced-vibration of ground filled with liquefied stabilized soil made from excavated Vinh Phuc clay in Hanoi city, Vietnam

\subsection{Underground traffic load}

As underground traffic load, the trains travel inside the tunnel are considered. There are many complains about vibration at houses near the tunnel. On the surface of the earth, it has been clarified that the vibration becomes large at a place slightly apart in transverse just above the tunnel. It has been reported that the vibration level of the ground surface which excels at $20 \mathrm{~Hz}^{7)}$ and solid sound having a peak at about $50 \mathrm{~Hz}$ or more even if it is below the vibration level threshold ${ }^{8)}$ may be a problem. In addition, there are large vibrations in the $63 \sim 80 \mathrm{~Hz}$ region, but there are also cases in which vibrations of $20 \sim 30 \mathrm{~Hz}$ have similar effect to ground vibration due to terrestrial trains ${ }^{6}$.

\subsection{Target distances and target frequencies}

This time, the open-cut tunnel is the target, and a road is directly above the tunnel. Therefore, we focused not only on the public-private boundary (near $10 \mathrm{~m}$ ) but also on subsequent vibrations, focusing on the range of 0 to $50 \mathrm{~m}$.

The target frequency was $0 \sim 40 \mathrm{~Hz}$ in this analysis. In addition to the viewpoints of (1) and (2), when a train is running in a tunnel and the ground rigidity is high, a high frequency of $40 \sim 100 \mathrm{~Hz}$ is likely to propagate. However, this time the target ground is relatively soft. Moreover, high frequency analysis requires a fine mesh and increases the analysis load. Therefore, the study of higher frequencies than above is a topic for the future.

\section{ANALYSIS CONDITIONS}

\subsection{Analysis model}

In this analysis, the ground conditions in Fig. 2 are modeled as shown in Fig. 3, focusing on shear elastic wave velocity and specific weight. The analysis is a frequency response analysis by two-dimensional FEM, the ground is modeled by a plane strain element and the open-cut tunnel is modeled by a beam element. Damping is modeled with complex stiffness. Damping constant is assumed at the time of infinitesimal deformation (shear strain $10^{-6}$ ) and its values are shown in railway standard ${ }^{4)}$ from $0.5 \%$ to $3 \%$ (soil quality (1) (4)) depending on the soil quality. Here the damping constant is chosen as $1 \%$, which is close to the lower limit. The element width of the analysis model is $0.5 \mathrm{~m}$ or $1.0 \mathrm{~m}$ depending on the ground rigidity so that the target frequency of $40 \mathrm{~Hz}$ can be considered.

The analysis area is $50 \mathrm{~m}$ on one side from the road center, but the model width is $100 \mathrm{~m}$ on one side in consideration of the influence of the boundary. The side is the energy transfer boundary and the bottom is the viscous boundary. The excitation points were the center of the road and the tunnel, and matched with the center of the analysis model area.

Table 2 shows the physical property values used in the analysis. The shear elastic wave velocity of the ground was calculated based on the Japanese railway standard ${ }^{4)}$ from the local $\mathrm{N}$ value.

As the backfill material, 2 cases of (1) general mountain sand with $\mathrm{N}=10$ and (2) liquefied stabilized soi ${ }^{1)}$ using generated soil from local construction sites are assumed as basic cases.

\subsection{Analysis cases}

Table 3 shows the analysis cases. Each case pays attention to the characteristics of backfill soil. The positioning of each case is as follows.

Cases 1 and 2 are considered as the basic cases. The case of normal backfill soil $(\mathrm{N}=10)$ is Case 1, and the liquefied stabilized soil assumed from laboratory tests is Case 2. 
Case 3 is normal soil with poor compaction, therefore $\mathrm{N}=5$. In addition, it can be regarded as the case where the rigidity of liquefied stabilized soil is intentionally lowered.

Cases 4 to 6 are cases in which the rigidity of the liquefied stabilized soil is changed. Cases 4 to 5 are cases where the rigidity is lower than the current assumption, and can be positioned as if the predetermined rigidity was not exhibited due to some influence. Case 6 is a case where the amount of cement is increased and the rigidity is higher than the current assumption. The liquefied stabilized soil has rigidity and strength that is not too hard, and is generally set to a level that allows for future excavation. Therefore, this rigid case is not realistic as liquefied stabilized soil, but it is a set value that investigated the possibility as a vibration countermeasure.

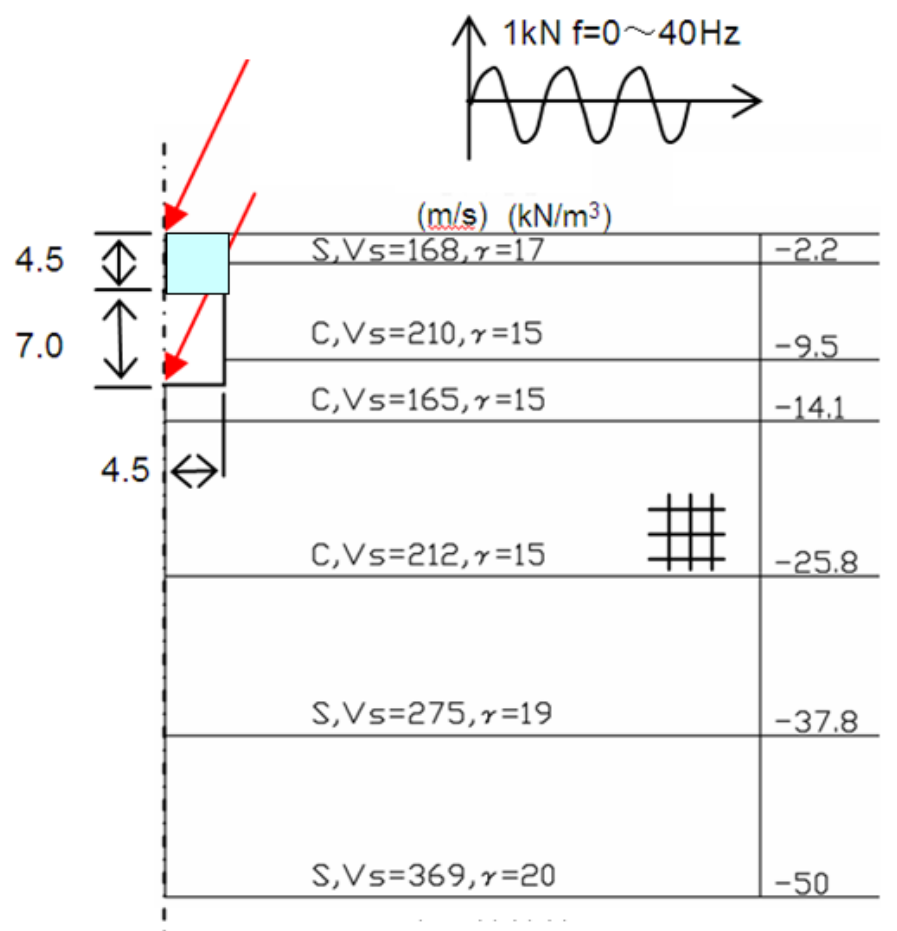

Road center (Width: 100m on one side)

Figure 3 Overview of the analysis model

Table 2 Physical property values in analysis (basic case)

\begin{tabular}{|c|c|c|c|c|c|c|c|}
\hline Depth (m) & $\begin{array}{l}\text { Layer } \\
\text { thickness (m) }\end{array}$ & & $\begin{array}{l}\text { Average } \\
\mathrm{N} \text { value }\end{array}$ & $\gamma$ & $\gamma\left(\mathrm{kN} / \mathrm{m}^{3}\right)$ & $\mathrm{G}\left(\mathrm{kN} / \mathrm{m}^{2}\right)$ & $\mathrm{Vs}(\mathrm{m} / \mathrm{s})$ \\
\hline 2.2 & 2.2 & $S$ & 9.3 & 0.49 & 17.0 & 48921 & 168 \\
\hline 9.5 & 7.3 & $C$ & 9.3 & 0.49 & 15.0 & 67447 & 210 \\
\hline 14.1 & 4.6 & C & 4.5 & 0.49 & 15.0 & 41720 & 165 \\
\hline 25.8 & 11.7 & $C$ & 9.5 & 0.49 & 15.0 & 68656 & 212 \\
\hline 37.8 & 12.0 & $S$ & 40.7 & 0.49 & 19.0 & 146735 & 275 \\
\hline 50.0 & 12.2 & $S$ & 98.3 & 0.49 & 20.0 & 278103 & 369 \\
\hline
\end{tabular}


Characteristics of traffic induced-vibration of ground filled with liquefied stabilized soil made from excavated Vinh Phuc clay in Hanoi city, Vietnam

Table 2.1 Physical Property Average

\begin{tabular}{|c|c|c|c|c|c|c|}
\hline & & $\begin{array}{l}\text { Average } \\
\mathrm{N} \text { value }\end{array}$ & $\gamma$ & $\gamma\left(\mathrm{kN} / \mathrm{m}^{3}\right)$ & $\mathrm{G}\left(\mathrm{kN} / \mathrm{m}^{2}\right)$ & $\mathrm{Vs}(\mathrm{m} / \mathrm{s})$ \\
\hline \begin{tabular}{|l|l|} 
Backfill soil & $\mathrm{N}=10$
\end{tabular} & $\mathrm{~S}$ & 10.0 & 0.49 & 17.0 & 51531 & 172 \\
\hline \multicolumn{3}{|c|}{ Liquefied stabilized soil *) } & 0.49 & 14.0 & 197200 & 370 \\
\hline
\end{tabular}

$*$ Laboratory test result (49kPa without fiber, E0 $=587.6 \mathrm{MN} / \mathrm{m} 2$ )

The specific weight of the liquefied stabilized soil is often lighter than general soil. However, the heavier weight is generally harder to vibrate, so in Case 7 the specific weight is increased to a dense soil level as a countermeasure against vibration. In Case 7, the shear stiffness was the same as in Case 2, and only the specific weight was changed.

Case 8 focuses on the attenuation of liquefied stabilized soil. In traffic vibration, the strain level of the ground is considered to be small and elastic. Therefore, the damping constant $\mathrm{h}=1 \%$ is considered. However, as a countermeasure against vibration it is considered to be advantageous that the internal damping of the medium transmitting the vibration is larger. Therefore in Case $8, \mathrm{~h}=10 \%$ is assumed. The material is assumed to be able to absorb the energy by drawing the hysteresis loop and plasticizing the ground even at a small strain.

In Case 9 it is assumed that the liquefied stabilized soil was applied to the area of the upper $4.5 \mathrm{~m}$ and the lower $2 \mathrm{~m}$ below the tunnel under the examination conditions in Figure 3, because there is a layer with less rigidity than the lower layer of about $2 \mathrm{~m}$ below the tunnel. Auxiliary construction methods that improve the ground near the bottom plate during excavation to ensure the stability of temporary earth retaining are common. This case is a study to confirm whether such auxiliary construction methods can be actively used as vibration countermeasures.

Table 3 Analysis cases

\begin{tabular}{|c|c|c|c|c|c|c|c|}
\hline & Open-cut & Ground & \multicolumn{4}{|c|}{ Backfill soil } & \multirow[b]{2}{*}{ Range } \\
\hline & & & Content & Vs $(\mathrm{m} / \mathrm{s})$ & $\begin{array}{c}\text { Unit } \\
\text { weight } \\
\left(\mathrm{kN} / \mathrm{m}^{3}\right)\end{array}$ & $\begin{array}{c}\text { Attenuation } \\
\mathrm{h}\end{array}$ & \\
\hline Case 1 & \multirow{9}{*}{ Exist } & \multirow{9}{*}{$\begin{array}{l}\text { Existing } \\
\text { ground }\end{array}$} & $N=10$ & 170 & 17 & \multirow{7}{*}{0.01} & \multirow{8}{*}{$\begin{array}{l}\text { Upper part } \\
(4.5 \mathrm{~m})\end{array}$} \\
\hline Case 2 & & & Stabilized soil & 370 & 14 & & \\
\hline Case 3 & & & $N=5$ & 140 & 17 & & \\
\hline Case 4 & & & \multirow{3}{*}{ Stabilized soil } & 200 & \multirow{3}{*}{14} & & \\
\hline Case 5 & & & & 300 & & & \\
\hline Case 6 & & & & 500 & & & \\
\hline Case 7 & & & \multirow{3}{*}{ Stabilized soil } & \multirow{3}{*}{370} & 20 & & \\
\hline Case 8 & & & & & \multirow[b]{2}{*}{14} & 0.1 & \\
\hline Case 9 & & & & & & 0.01 & $\begin{array}{l}\text { Upper and } \\
\text { lower part }\end{array}$ \\
\hline
\end{tabular}

\subsection{Evaluation method}

The excitation position is the ground surface and the inside of the subway. The vertical unit excitation force $(1 \mathrm{kN})$ with the frequencies varying from 0 to $40 \mathrm{~Hz}$ in the increment of 0.5 $\mathrm{Hz}$ is applied to investigate the ground surface acceleration. The acceleration in the vertical direction $\mathrm{VAL}=20 \cdot \log 10\left(\mathrm{~A} / \mathrm{A}_{0}\right), \mathrm{A}_{0}=10^{-5} \mathrm{~m} / \mathrm{sec}^{2}$ is focused and converted to vibration acceleration level VAL $(\mathrm{dB})$ for evaluation. Since the response is due to unit excitation force, this result is called the transfer function. 


\section{VIBRATION REDUCTION EFFECT BY LIQUEFIED STABILIZED SOIL}

\subsection{Vertical vibration component}

\subsubsection{Transfer function}

As a representative of Case 1 and Case 2, the overall vibration reduction effect is discussed.

First, Fig. 4 shows the distance attenuation from the transfer function of surface excitation and underground excitation for typical frequencies of Case 1 and 2. "Co" in the legend means Case in Table-3. Note that these are reference values because they are responses (transfer functions) to the unit excitation force, not actual traffic vibration values. However, the relative difference in vibration value is significant when the normal backfill soil $(\mathrm{N}=10)$ is changed to liquefied stabilized soil. This shows the following.

- Surface excitation of (1) changes little at $5 \mathrm{~Hz}$ and increases or decreases depending on the location at $20 \mathrm{~Hz}$. At 10 and $30 \mathrm{~Hz}$, vibration decreases at any distance in liquefied stabilized soil.

- For ground vibration of (2), the overall reduction effect is less than surface vibration. There are few changes at $5 \mathrm{~Hz}$ and there are many points where the vibration decreases at $20 \mathrm{~Hz}$, but the vibration tends to increase at $10 \mathrm{~Hz}$. At $30 \mathrm{~Hz}$, it increases and decreases with distance.

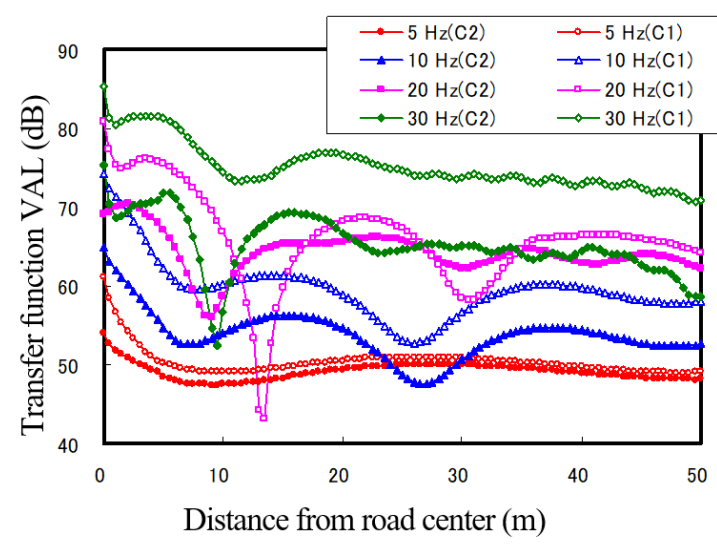

(1) Surface excitation

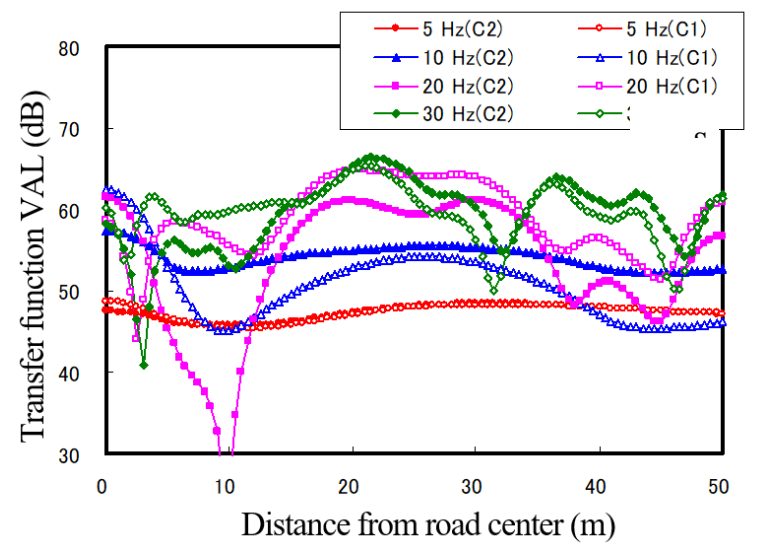

(2) Underground excitation

Figure 4 Transfer function (vertical component, Case 1, Case 2)

\subsubsection{Overall vibration reduction effect}

Here, although the vibration reduction effect varies from point to point, the average value of the vibration difference (Case2-Case1) of $0 \sim 50 \mathrm{~m}$ is calculated as an index that represents the overall vibration reduction effect, and is shown in Figure 5. In the case of ground surface excitation, it is less effective at $14 \sim 18 \mathrm{~Hz}$, but generally effective at other frequencies. It can be seen that ground excitation decreases at $18 \sim 30 \mathrm{~Hz}$ but increases at $6-18 \mathrm{~Hz}$ and at $30 \mathrm{~Hz}$ or bigger.

Therefore, liquefied stabilized soil is more effective in reducing vibration against ground vibration due to surface excitation.

From Fig. 5 (2), in the liquefied stabilized soil with surface excitation, the vibration decreases at the excitation point, and the trend of distance reduction thereafter is the same with 
mountain sand. On the other hand, in the case of underground excitation, it is not a uniform tendency but complicated. In ground excitation, there is a backfill part in the excitation part, and the excitation force is simply dispersed. The vibration value decreases but the tendency of distance attenuation does not change so much. On the other hand, in underground excitation, the propagation path above the structure has changed, and the vibration characteristics are considered to change in a complex manner.

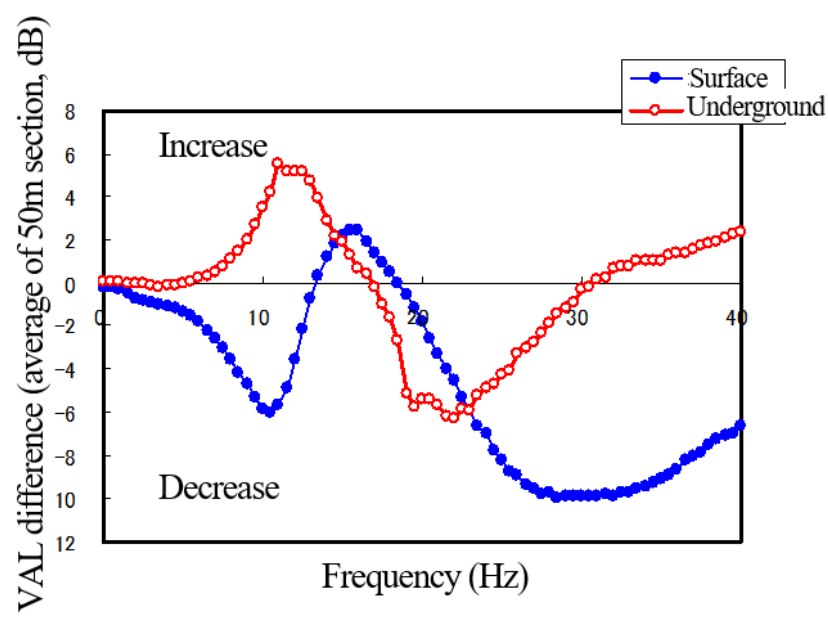

Figure 5 Vibration reduction effect of liquefied stabilized soil (vertical component)

\subsection{Horizontal vibration component}

\subsubsection{Transfer function}

Fig. 6 shows the transfer function, Fig. 7 shows the difference in the vibration acceleration level of the horizontal vibration component in the same manner as the vertical vibration component.

Figure 6 shows that the positions of the peaks and valleys of the vibration are different from the vertical component. For example, when focusing on $20 \mathrm{~Hz}$, the vertical component has a valley near $10 \mathrm{~m}$, but the horizontal component does not become a valley there but near $20 \mathrm{~m}$. This indicates the danger of judging that if a certain vibration component has little vibration then the vibration of another component is also small.

It can also be seen that the vibration attenuates as the vibration value increases or decreases depending on distances and points. From this, it is conceivable that it is important to grasp the vibration value continuously as far as possible because the evaluation of vibration at one specific point may be different from the whole vibration tendency.

\subsubsection{Overall vibration reduction effect}

In terms of individual vibration components, the vibration characteristics differ vertically and horizontally. Here, as with the vertical component, the vibration reduction effect is investigated using the average value of vibration difference of $50 \mathrm{~m}$. The result is shown in Fig.7. Compared to the vertical case in Fig. 5, the influence is slightly smaller than the surface excitation, but the trend is almost the same.

From this, the vibration evaluation may increase or decrease at a single point, but overall, liquefied stabilized soil can also be expected to reduce the vibration of the horizontal component. 


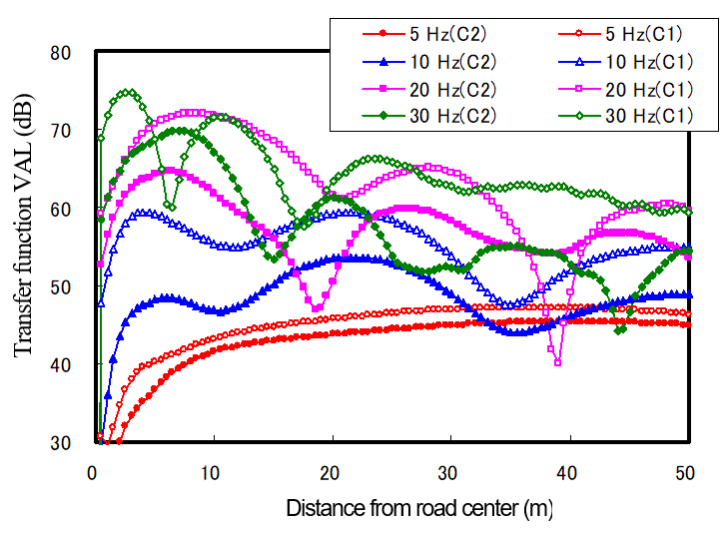

(1) Surface excitation

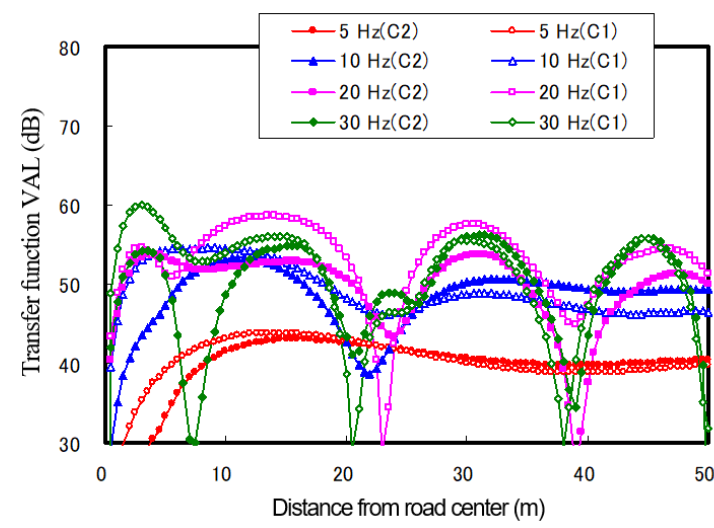

(2) Ground excitation

Figure 6 Transfer function (horizontal component, Case1, Case2)

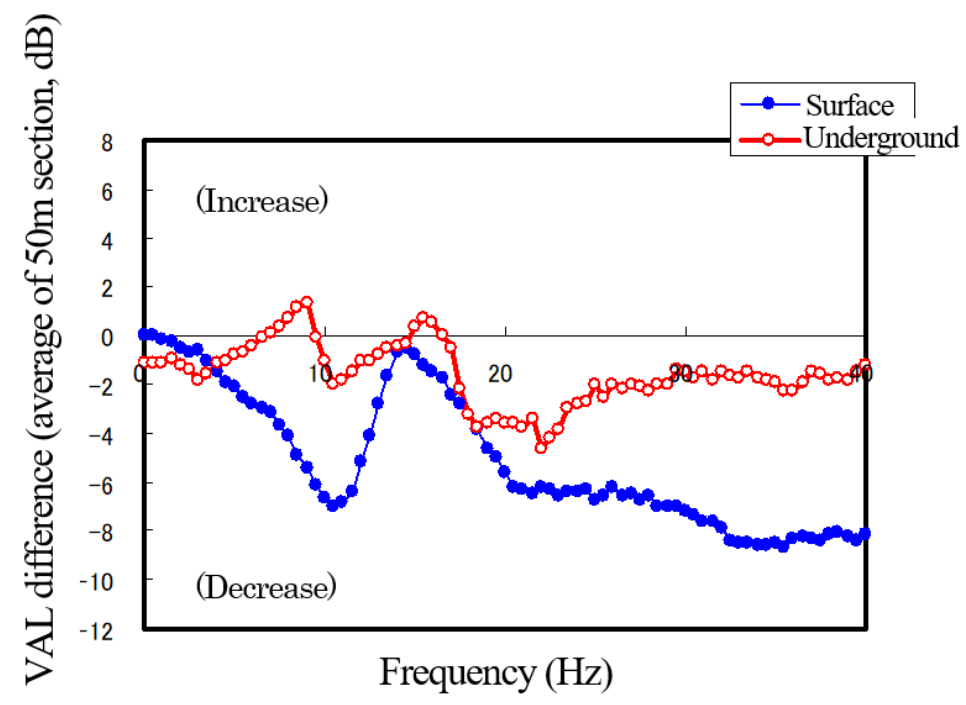

Figure 7 Vibration reduction effect of liquefied stabilized soil (horizontal component)

\section{CHARACTERISTICS OF BACKFILL SOIL AND GROUND VIBRATION REDUCTION EFFECT}

The effect of ground vibration reduction when changing the characteristics of backfill soil is examined. Here, as a general effect, the average vibration reduction characteristics in the $50 \mathrm{~m}$ section are examined.

Figure 8 shows the average value of the transfer functions of Case 1 9 in Table 3 for the $50 \mathrm{~m}$ section, and Figure 9 shows the difference between Case 1 (landfill $\mathrm{N}=10$ ) and other cases. This shows the following.

- Focusing on Case $3(\mathrm{~N}=5)$ as the effect of compaction, the vibration increases up to about $5 \mathrm{~dB}$ compared to $\mathrm{N}=10$.

- Focusing on Case 4 6 as the effect of rigidity, it can be seen that the higher the rigidity, the higher the vibration reduction effect.

- As the effect of specific weight, when Case $7(\gamma=20 \mathrm{kN} / \mathrm{m} 3)$ and Case $2\left(\gamma=14 \mathrm{kN} / \mathrm{m}^{3}\right)$ are compared, the vibration of Case $7\left(\gamma=20 \mathrm{kN} / \mathrm{m}^{3}\right)$ is smaller at $15 \sim 30 \mathrm{~Hz}$ but the 
Characteristics of traffic induced-vibration of ground filled with liquefied stabilized soil made from excavated Vinh Phuc clay in Hanoi city, Vietnam

vibration of Case $2\left(\gamma=14 \mathrm{kN} / \mathrm{m}^{3}\right)$ is smaller at other frequencies. It should be noted that even if the unit weight increases, the reduction effect is not uniform in all ranges.

- As the effect of damping, when Case $8(\mathrm{~h}=10 \%)$ and Case $2(\mathrm{~h}=1 \%)$ are compared, there is almost no change at low frequencies, and the difference is as low as $2 \mathrm{~dB}$ even at $30 \mathrm{~Hz}$ or higher. It is probable that the damping was increased only in the backfilled part, and the proportion of the damped part in the vibrating ground was small.

- The effect of the improvement of the open-cut tunnel bottom plate shows little change from the comparison between Case 9 and Case 2. Figure 9 shows that the influence of the bottom of the open-cut tunnel was small due to surface vibration. In addition, it was confirmed that the influence was small even with underground excitation, and it is considered that the difference in rigidity between the bottom of the bottom plate and its lower layer was not so large.

\section{VIBRATION REDUCTION EFFECT AT EACH POINT}

The evaluation at each point is performed. The target is ground surface excitation.

Fig.10 Fig.13 show the transfer function from the excitation point to $0 \mathrm{~m}$ (excitation point), $10 \mathrm{~m}$ and $20 \mathrm{~m}$, and the increase / decrease of vibration for the mountain sand in Case1.

\subsection{0m (excitation points)}

Here we pay attention to the excitation point in Fig. 10. From Fig. 10 (2), it can be seen that Case 1 is the standard, and the case where the shear elastic wave velocity in the backfill portion is high, which is the case with higher rigidity, has a higher reduction effect. In particular, since $0 \mathrm{~Hz}$ is equal to static displacement, the vibration reduction effect becomes smaller as Vs becomes smaller in the following order: Case $6(\mathrm{Vs}=500 \mathrm{~m} / \mathrm{s})$ which is the smallest, Case 2 and 7, 8, $9(\mathrm{Vs}=370 \mathrm{~m} / \mathrm{s})$ which are comparable, and Case $5(\mathrm{Vs}=300 \mathrm{~m} / \mathrm{s})$.

Focusing on Case 2 and Case 7, 8, 9 with the same $\mathrm{Vs}=370 \mathrm{~m} / \mathrm{s}$, it is about the same up to about $12 \mathrm{~Hz}$. However Case 7 which has a large unit weight has the greatest reduction effect from about $12 \sim 20 \mathrm{~Hz}$, but it is not much different from other cases at high frequencies of 20 $\mathrm{Hz}$ or more.

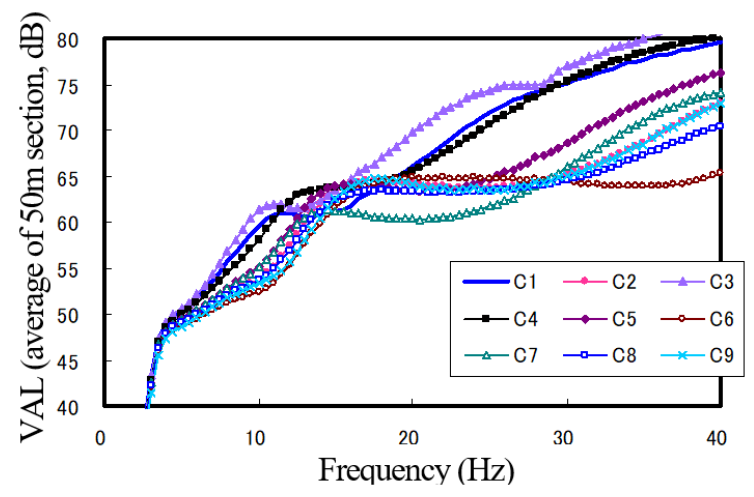

(1) Vertical component

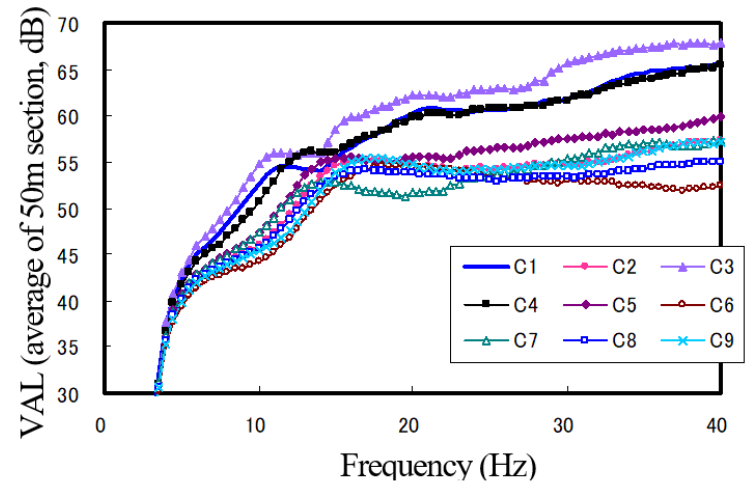

(2) Horizontal component

Figure 8 Transfer function (surface excitation, with tunnel) 


\subsection{0 m point}

Focusing on the 10m point in Fig. 11, it can be seen from (1) of this figure that when basing on Case 1, Case 1 has a valley at $15 \mathrm{~Hz}$, and from (2) of this figure that when comparing with Case 1 at $15 \mathrm{~Hz}$, the vibration increases. As also can be seen from Fig. 1 (1), this is an evaluation that is caused by focusing on only a single frequency rather than by increasing the vibration. An actual vibration includes many frequencies and the valley of an extreme vibration is hard to occur due to the disorder of the layer composition. In consideration of this point, the evaluation except for around $15 \mathrm{~Hz}$ shows that at $0 \mathrm{~m}$ (excitation point) the vibration reduction effect is small around $10 \mathrm{~Hz}$, but the vibration reduction effect can be expected at frequencies higher than $20 \mathrm{~Hz}$. At $10 \mathrm{~m}$ point, it can be seen that the reduction effect is hardly expected especially at low frequency close to the static displacement of $0 \sim 5 \mathrm{~Hz}$.

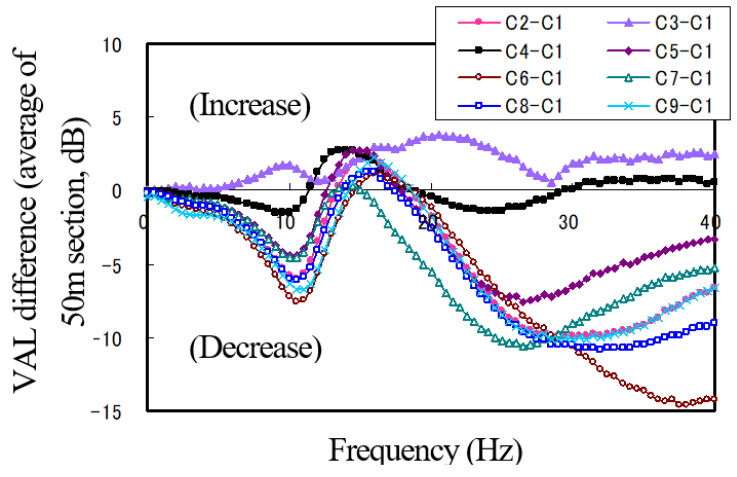

(1) Vertical component

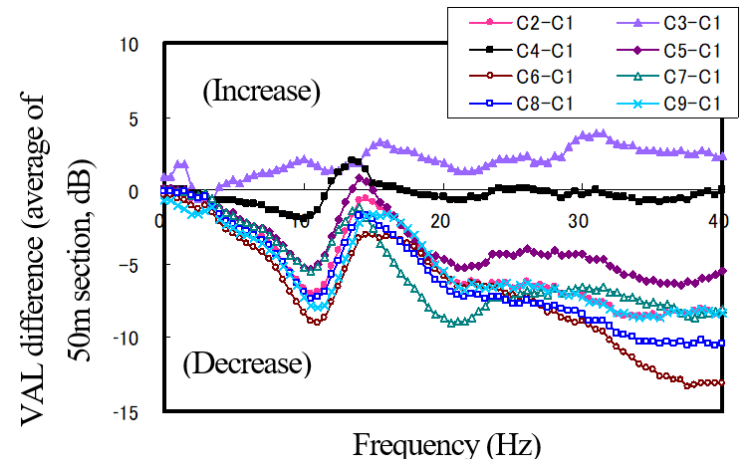

(2) Horizontal component

Figure 9 Vibration reduction effect for Case 1 (surface excitation, with tunnel)

\section{3. $20 \mathrm{~m}$ point}

As shown in Fig. 12 (1), at $20 \mathrm{~m}$ point, there is no extreme vibration valley like at $10 \mathrm{~m}$ point at $15 \mathrm{~Hz}$ in Case 1, but the vibration reduction effect is still small around $15 \mathrm{~Hz}$. In Case 2 and $7,8,9(\mathrm{Vs}=370 \mathrm{~m} / \mathrm{s})$, the vibration tends to decrease at frequencies higher than $20 \mathrm{~Hz}$ in Fig. 11 (1) at $10 \mathrm{~m}$, but increase in Fig. 12 (1) at $20 \mathrm{~m}$. As a result, the vibration increased slightly near $20 \mathrm{~m}$.

VAL (dB)

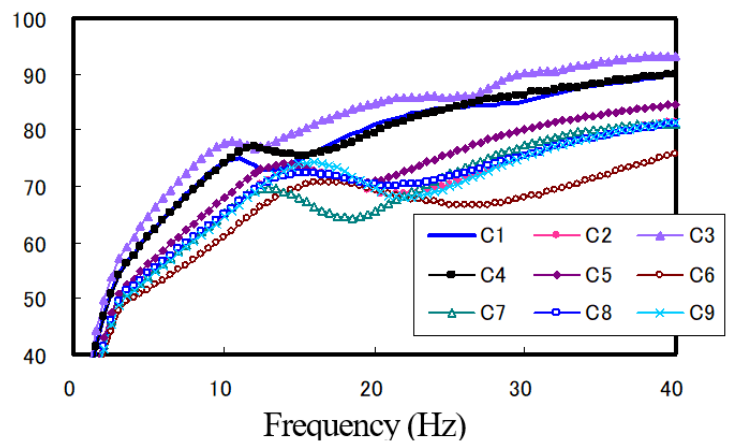

(1) Transfer function

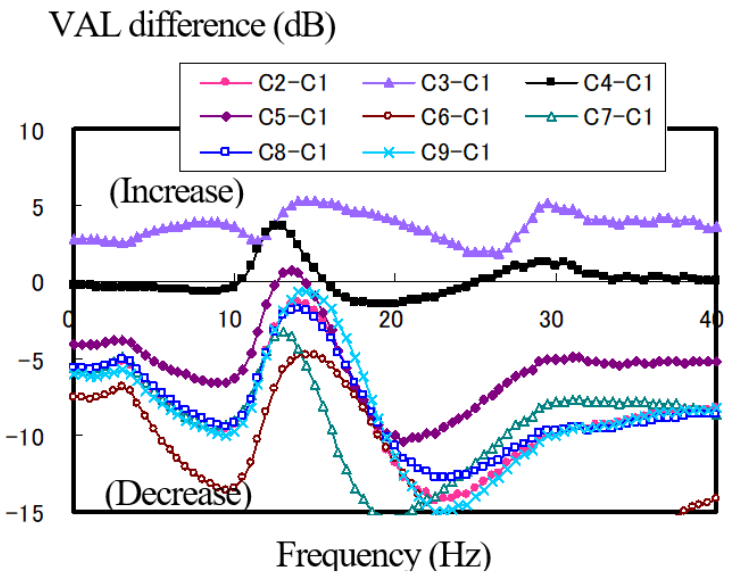

(2) Difference from Case 1

Figure 10 Transfer function (Distance $0 \mathrm{~m}$, excitation point) 


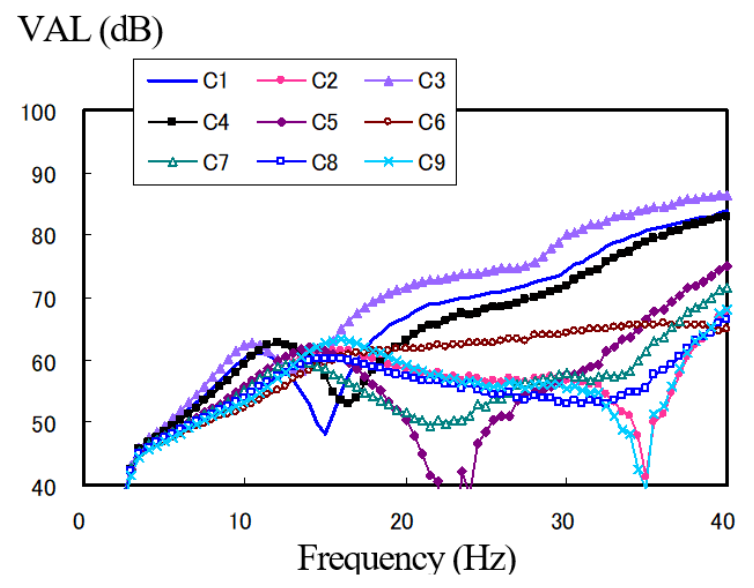

(1) Transfer function
VAL difference $(\mathrm{dB})$

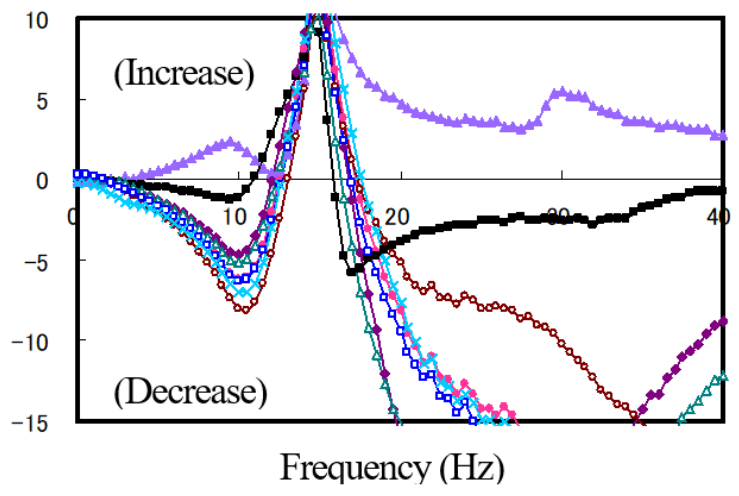

(2) Difference from Case 1

Figure 11 Transfer Function (Distance $10 \mathrm{~m}$ )

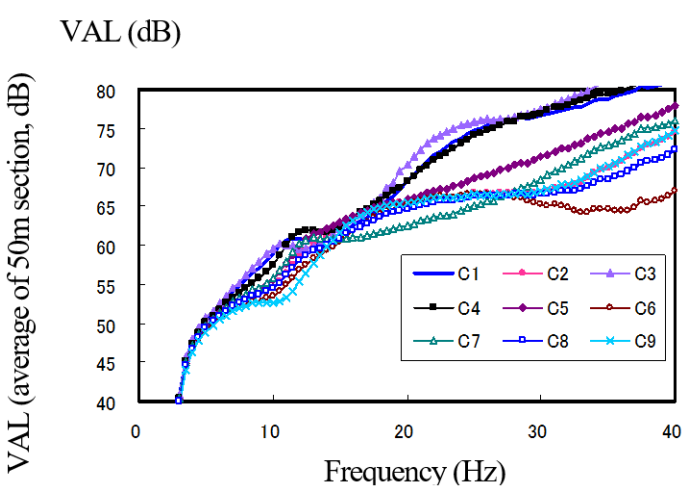

(1) Transfer function
VAL difference $(\mathrm{dB})$

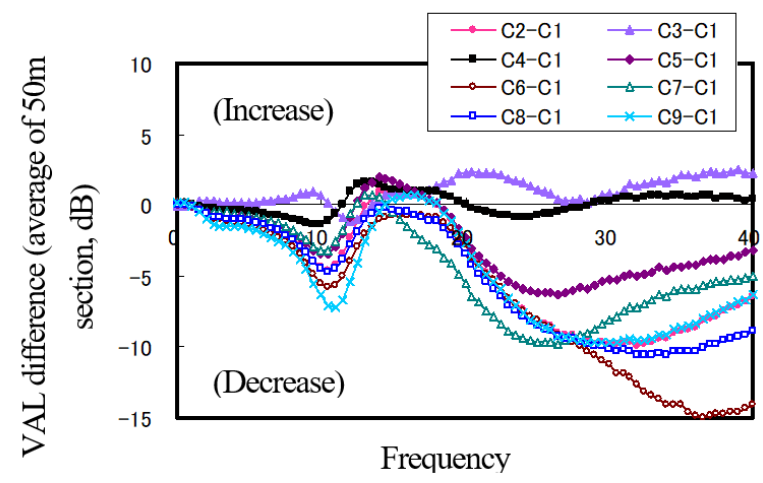

(2) Difference from Case 1

Figure 12 Transfer Function (Distance $20 \mathrm{~m}$ )

\section{VISUALIZATION OF GROUND VIBRATION DISPLACEMENT BY SURFACE EXCITATION AND UNDERGROUND EXCITATION}

The visualization of ground vibration displacement caused by surface vibration and underground vibration is used to examine the phenomena where the vibration increases and decreases according to the distance and its property changes greatly depending on the frequency.

\subsection{In the case of surface excitation}

Fig. 13 shows the displacement trajectory of Case 1 (backfilling: $\mathrm{N}=10$ ) and Fig. 14 shows the displacement trajectory of Case 2 (backfilling: liquefied stabilized soil) when an open-cut tunnel exists. The scale of the displacement is adjusted by multiplying by the appropriate magnification of each frequency.

The average shear wave velocity of the surface layer is $200 \mathrm{~m} / \mathrm{s}$, and the wavelength becomes $200 / 5=40 \mathrm{~m}$ at $5 \mathrm{~Hz}$ excitation. Similarly, it is $20 \mathrm{~m}$ at $10 \mathrm{~Hz}$ and $10 \mathrm{~m}$ at $20 \mathrm{~Hz}$. As looking at the trajectory of the ground surface, at $5 \mathrm{~Hz}$ the vibrations were uniform at a distance (Figure 13a), but at higher frequencies, such as $20 \mathrm{~Hz}$, the increase and decrease of the vibrations became conspicuous. It can be seen that there are places where the amplitude 
increases and decreases due to interference near the stratum boundary in part (b) of the same figure.

In addition, although the $20 \mathrm{~Hz}$ vertical vibration discussed in Fig. 4 and Fig. 6 has a valley near $12 \mathrm{~m}$, it can be confirmed that a horizontal vibration component exists at the same position.

From Fig. 14, it can be seen that in the case of $20 \mathrm{~Hz}$, the use of liquefied stabilized soil reduces the vibration as a whole. (Figure 13 (3) and Figure 14 have the same scale).

From these figures, the existence of vibration reduction effect as shown in Fig. 4 is examined. Since the backfill is only at the upper part of the tunnel, when using liquefied stabilized soil at long wavelengths such as $5 \mathrm{~Hz}$, a decrease in static displacement is expected near the excitation point. However it is considered that at the wavelength of $5 \mathrm{~Hz}(40 \mathrm{~m})$ the influence of the backfilled part is hard to appear because the ratio of the backfilled part becomes very small. Conversely, it is considered that the influence of the backfill part is likely to appear at a wavelength of $20 \mathrm{~Hz}(5 \mathrm{~m})$.

\subsection{In the case of underground excitation}

The displacement trajectory for the case of underground excitation is also shown in Fig. 15 and Fig. 16. These are plotted on a displacement scale twice that of Fig. 13 and 14.

In Fig. 15 (1), the lower floor slab is vibrated at $5 \mathrm{~Hz}$, but the upper slab and the backfill part do not vibrate partially but behave as a whole. You can see

On the other hand, with the $10 \mathrm{~Hz}$ excitation shown in Fig. 15 (2), it can be seen that not only the lower floor slab but also the center of the upper floor slab (part c of the same figure) vibrated well.

At around $20 \mathrm{~Hz}$ in Fig. 15 (3), it can be seen that the upper deck slab hardly vibrates and only the lower deck slab (part c of the same figure) vibrates.

The displacement trajectory in the case of $20 \mathrm{~Hz}$ excitation shown in Fig. 16 where the backfilled part is liquefied stabilized soil has the same tendency as that in Fig. 15 (3), but it can be seen that in the vicinity near the side wall it is smaller than Fig. 15 (3).

As an example of comparing the surface excitation with the underground excitation, for the ground surface in Fig. 13 (3) and Fig. 15 (3), the vertical vibration is small at around $12 \mathrm{~m}$ and $30 \mathrm{~m}$ in Fig. 13 and it looks like a node of vibration. However it can be seen in Fig. 15 that at around $30 \mathrm{~m}$ the vertical vibration becomes large, the amplitude does not simply decrease according to the distance, and the fluctuation of the vibration changes complicatedly due to the interference of vibrations from the surface and from underground.

\section{CONCLUSION}

In this study, we focused on the backfill soil in the open-cut tunnel. Analytical considerations were made using a two-dimensional FEM. The target frequency in this study was from 0 to 40 $\mathrm{Hz}$.

The evaluation was performed using the difference of the transfer functions of acceleration between normal backfill soil and liquefied stabilized soil as the main index. The survey was conducted not only for the average section, but also for the excitation point as well as points $10 \mathrm{~m}$ and $20 \mathrm{~m}$ from the excitation point.

- Improving backfill using liquefied stabilized soil has the effect of reducing ground vibration caused by ground surface traffic loads.

- The effect of liquefied stabilized soil on the reduction of ground vibration is not as effective for the train load inside the tunnel as for the ground traffic load. 
- Looking at the vibration reduction effect at each distance, in the case of surface vibration, at the excitation point even low vibration up to about $5 \mathrm{~Hz}$ has the reduction effect by using liquefied stabilized soil, but this effect decreases as the distance increases to $10 \mathrm{~m}$ or $20 \mathrm{~m}$.

- At high frequencies such as $20 \mathrm{~Hz}$, it was found that in the case of normal soil the reduction effect of liquefied stabilized soil was difficult to appear in some places where the ground vibration became a node and the vibration was small.

Furthermore, as a result of studying the vibration characteristics by visualizing the vibration displacement trajectory, the following considerations could be recognized again when examining vibration countermeasures.

- Vibration evaluation at a point differs depending on whether the focus is on vertical or horizontal vibration.

- The vibration characteristics differ between surface excitation and underground excitation, and the vibration of the ground surface changes complicatedly due to the influence of the propagation path.

From the above, liquefied stabilized soil, which has been useful from the viewpoint of environmental conservation and workability, is also effective as a measure against traffic vibration which means that a new advantage of liquefied stabilized soil was pointed out.

However, since the analysis in this case is an evaluation based on a virtual excitation force using a sine wave, it is possible that the nodes of the vibration may have appeared remarkably. The evaluation focuses on the difference between the transfer functions. In the future, it is necessary to study the excitation source as a traffic load by using excitation waveforms that are closer to actual conditions.

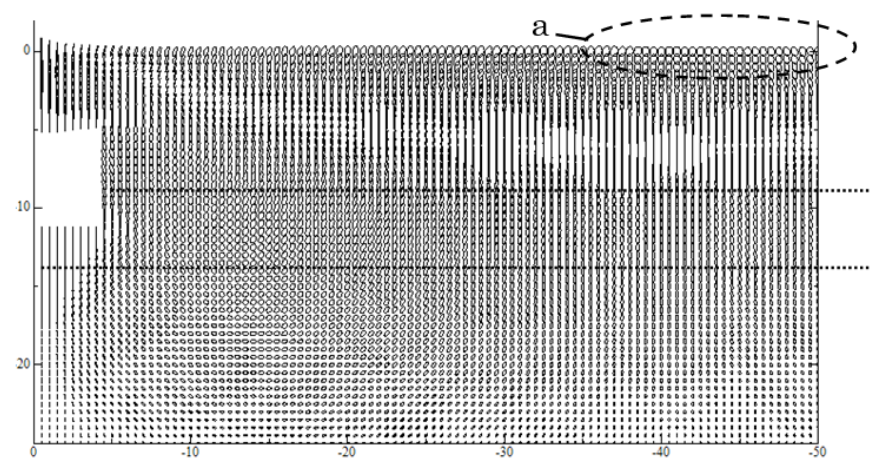

(1) $5 \mathrm{~Hz}$ excitation

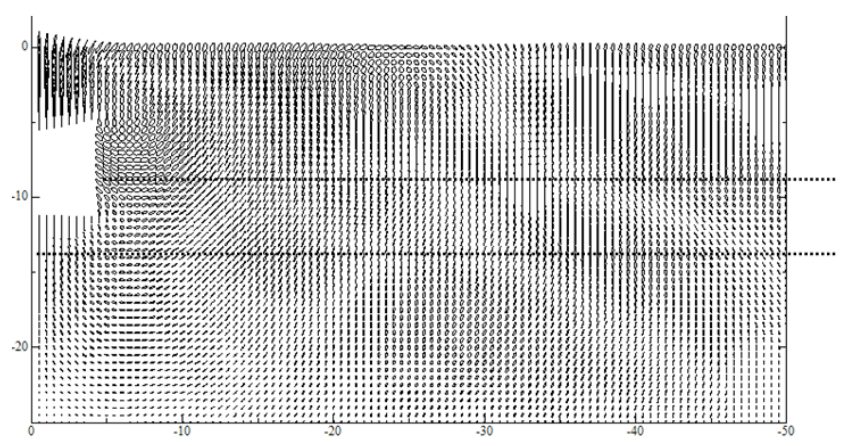

(2) $10 \mathrm{~Hz}$ excitation

http://www.iaeme.com/IJCIET/index.asp 50 editor@iaeme.com 


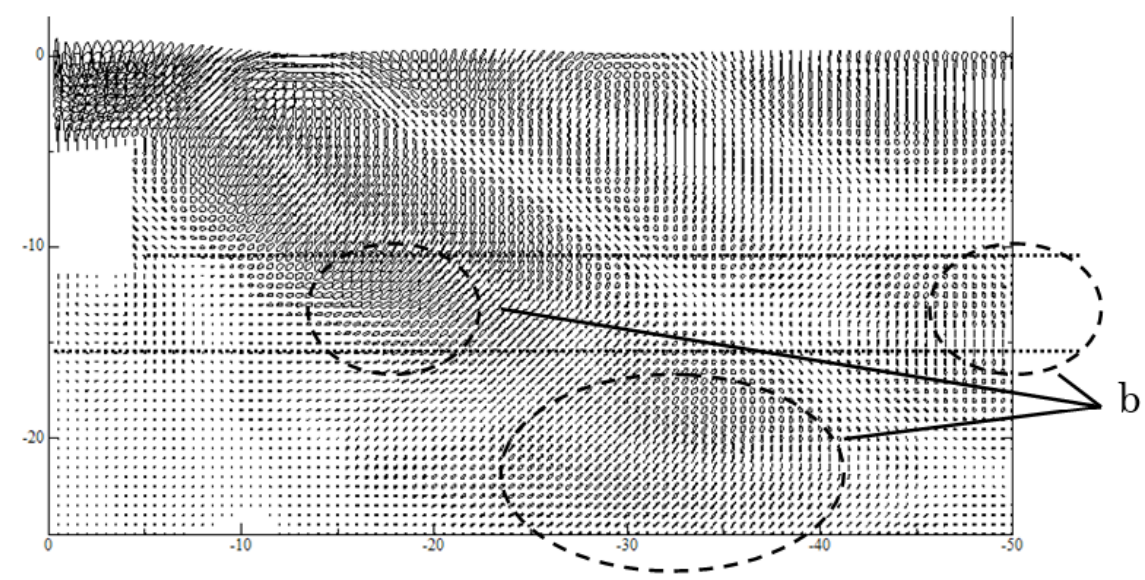

(3) $20 \mathrm{~Hz}$ excitation

Figure 13 Case 1 (Backfill: $\mathrm{N}=10$ ) Surface excitation

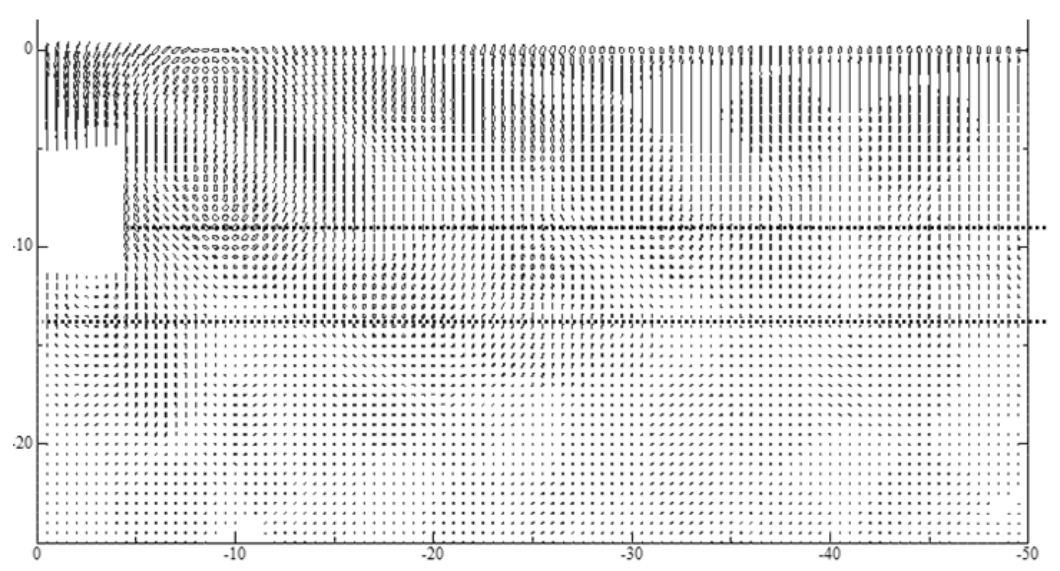

Figure 14 Case 2 (Backfill: liquefied stabilized soil) Surface excitation

(20 Hz excitation)

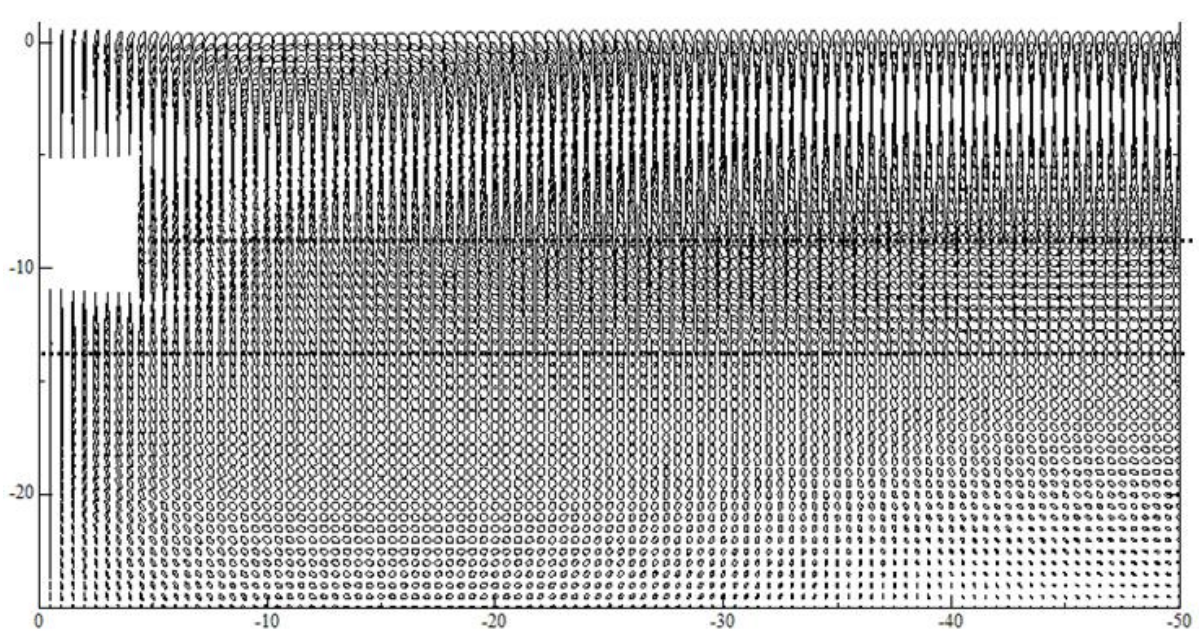

(1) $5 \mathrm{~Hz}$ excitation 
Characteristics of traffic induced-vibration of ground filled with liquefied stabilized soil made from excavated Vinh Phuc clay in Hanoi city, Vietnam

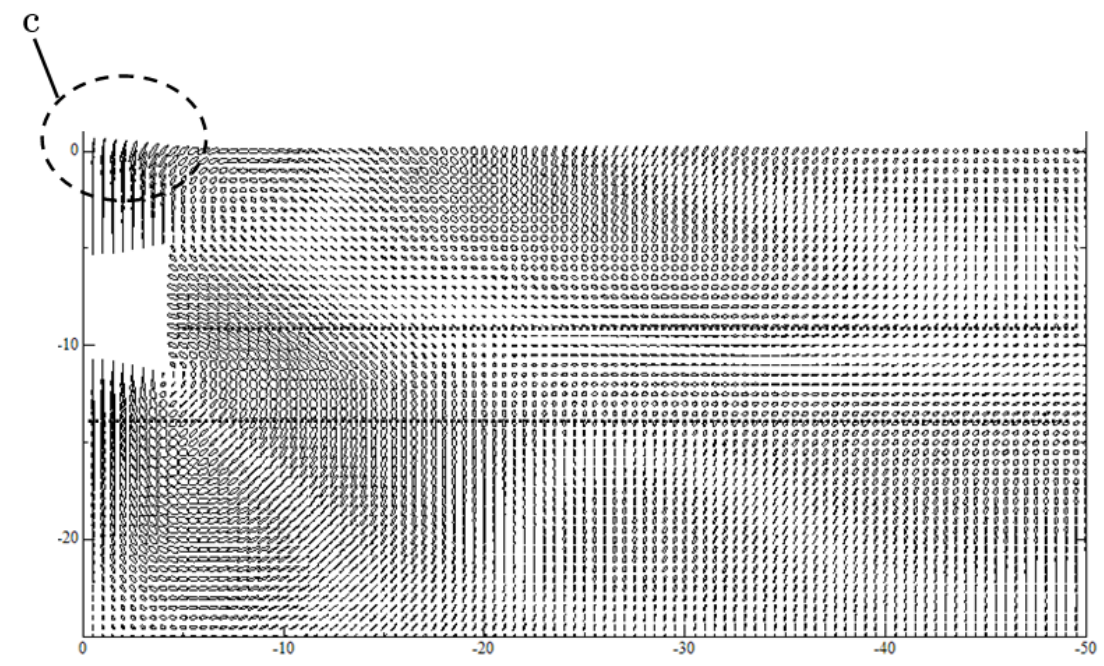

(2) $10 \mathrm{~Hz}$ excitation

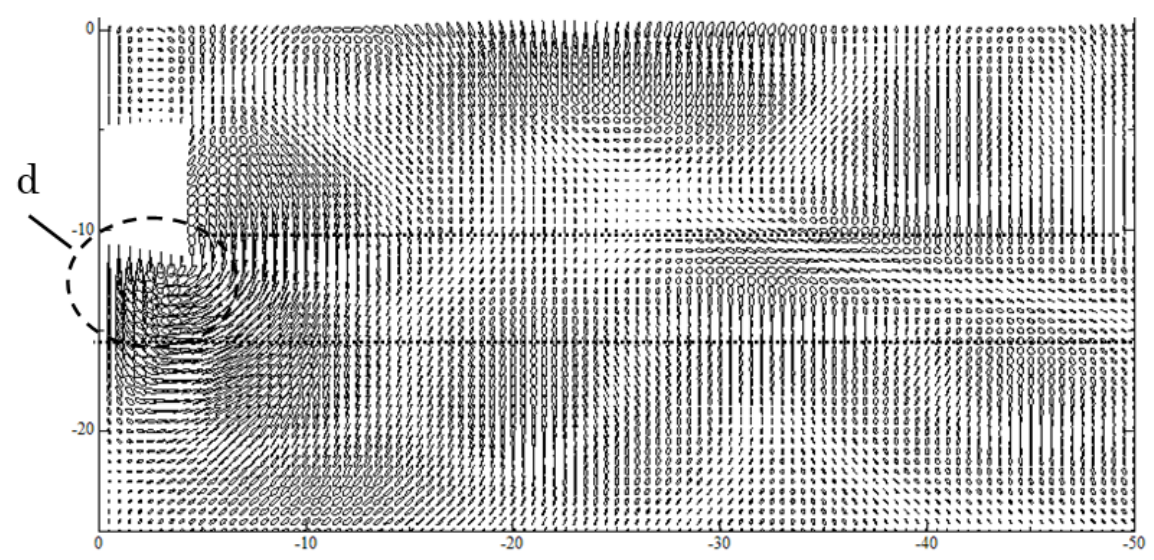

(3) $20 \mathrm{~Hz}$ excitation

Figure 15 Case 1 (Backfill: $\mathrm{N}=10$ ) Underground excitation

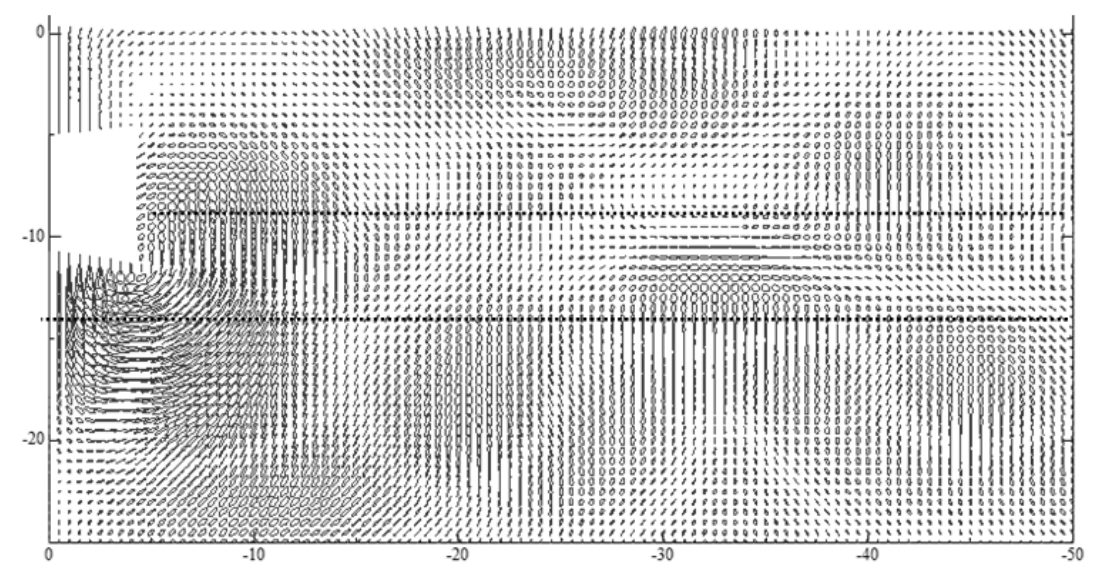

Figure 16 Case 2 (Backfill: liquefied stabilized soil) Underground excitation

(20 Hz excitation) 


\section{REFERENCES}

[1] Seiji Nishiyama, Nguyen Cong Giang, Yukihiro Kohata, Takao Sugimoto, Masaaki Katagiri. Characteristics of traffic induced vibration of ground on back fill materials for cut and cover tunnel, Journal of applied mechanics Vol. 12, pp. 1053-1060, 2009 (in Japanese)

[2] Yukihiro Kohata, Masatsugu Ichikawa, Nguyen Cong Giang, Yuichi Kato. Study of the damage properties of liquefied stabilized soil reinforced by fiber material on triaxial shearing. Geosynthetics Engineering Journal, Vol. 22, pp. 55-62, 2007 (in Japanese)

[3] Teruo Yamato, Toshio Umehara, Hifumi Aoki, Susumu Nakamura, Jyunichi Ezaki, Iwao Suetomi. Damage to Daikai subway station of Kobe rapid transit system and estimation of its reason during the 1995 Hyogoken-Nanbu earthquake, Journal of Japan Society of Civil Engineers Vol. 1996 No. 537 pp 303-320, 1996 (in Japanese)

[4] Railway structure design standards and explanations Seismic design: Railway Technical Research Institute, 1999 (in Japanese)

[5] Atsushi Ejima: Ground vibration and countermeasures, Shubun, 1979 (in Japanese)

[6] Kiyoshi Hayakawa: Mitigation measures of subway vibration by improved track, Journal of Japan Society of Civil Engineers, No.659 / III-52, 17-25, 2000 (in Japanese)

[7] Tsutomu Watanabe, Hidefumi Yokoyama, Yasushi Takei: Ground vibration analysis on railway tunnel, RRR 2008.10 (in Japanese)

[8] Kazuo Tsuno, Masaru Furuta, Koujiro Fujii, Fumio Nagashima, Osamu Kusakabe: Damping characteristics of broadband vibration propagating from shield tunnel in subway, Journal of Japan Society of Civil Engineers, No.792 / III-71, 185-197, 2005 (in Japanese)

[9] Nguyen Cong Giang, Nakayama Toshio, Sugimoto Takao, Kojima Yoshitaka, Katagiri Masaaki, Ohishi Kanta, Kohata Yukihiro. Considerations of Holocene Ground and Its Soil Properties in Hanoi City, Earth Science Vol 69, ISSN 0366-6611, pp 311-324, 2015 